\title{
INNOVATION IN THE VALUE CHAIN OF WOOD PRODUCTS: DATA, EQUATIONS AND LIFE-CYCLE ANALYSIS
}

\begin{abstract}
This chapter represents a review of the state of the art of the techniques and methodologies described and used in Lizarralde et al., 2008. Several issues have been reviewed and updated, while the work area and most of data remain equal, as an exercise of methodology review. Assessment of $\mathrm{CO}_{2}$ sequestration on wood products starts to raise importance when measuring the global sequestration in a forest. In this work, a more accurate estimation of $\mathrm{CO}_{2}$ on wood products is proposed, taking into account not only the volume but the useful life of those products. In order to estimate this carbon uptake and sequestration, innovation in forestry reveals new technologies and methodologies such as forest inventory using LiDAR technology or advanced modelling techniques. Besides, a new accountability and legal framework is added to review the state of the art of this particular issue. With this new information and knowing yield data of transformation of these products in final commercial products, the sequestration rate of each product and its useful life, we will be able to calculate the global sequestration of annual cuttings in an important and well-known forest in Spain.
\end{abstract}

\section{INTRODUCTION}

During the last decade, since the Kyoto Protocol came into effect on February, 2005, thousands of publications have been released related to the accomplishment of the protocol and the ways to measure the carbon fluxes all around the world. From the point of view of forests, it was considered as a great opportunity to enhance the value of our forests, beyond the traditional accounting of wood production and its value.

Although the accounting methodology of the sequestration proposed during the first commitment period (2008-2012) by the UNFCCC (United Nations Framework Convention on Climate Change) through the IPCC (Intergovernmental Panel on Climate Change) did not take into account the forest products as carbon sink (IPCC, 2000a), assuming that all carbon in the harvested biomass is oxidised in the removal year (Dias et al., 2005), several countries and the UNFCCC recognized the important role products can play on the global accounting. Thus, it was not until the second commitment period (2013-2020) when new opportunities to wood products (IPCC, 2014) were opened.

Besides, in a context where the European Union started defining the inclusion of wood products into the global carbon accounting, especially with the 2012

1

F. Bravo et al (eds.), Managing Forest Ecosystems: The Challenge of Climate Change, $\mathrm{x}-$ $\mathrm{xx}$.

(C) 2016 Kluwer Academic Publishers. Printed in the Netherlands. 
resolution (COM, 2012), positioning wood products in an starting lane as low carbon products becomes an important aim for researchers and the industry. And this aim can only be accomplished with feasible and economically available data for research bodies, consultings and wood industry. Data of life cycle analysis, carbon footprint and useful life of products will help mitigating climate change and enhancing national carbon budgets while allowing the active participation of citizen in the fight against climate change.

As is known, a large part of the carbon remains stored in long-lived wood products and persists for decades (IPCC, 2000b). Furthermore, wood may indirectly reduce carbon emissions since it can be a substitute material for steel or concrete in construction (Werner et al., 2005). The use of wood products is one of the few mitigation strategies that do not involve added economical cost. In summary, the calculation and promotion of carbon footprint for wood products in a feasible and reachable way is analysed, allowing both the development of new mitigation strategies and a better situation of national carbon budgets. Forest modeling techniques can be very useful tools for the accounting of carbon fixation in forests, and more precisely, in forest products. Forest models have normally been widely used for yield and growth estimation of our forest, but the link with the sequestration of $\mathrm{CO}_{2}$ has not been significantly explored. New approaches of forest model assessment become very useful for carbon accounting purposes.

In order to make an approach to this linkage, different examples are here described. On the one hand, a typical, well-known forest in Spain has been used: "Pinar Grande" is one of the largest public-managed forests in Soria (Northern Iberian Range, Spain) with an extension of over 12,500 ha, where Scots pine (Pinus sylvestris L.) occupies around $70 \%$ of the forest. Moreover, it was one of the first forests in Spain to have a management plan (it is now 100 years since the first plan). On the other hand, classical and new management paths for the species are compared, including material substitution rates and fluxes. The main aim of this chapter is thus to assess, with real data, the importance of wood products on carbon fixation.

\section{ESTIMATION OF CARBON STOCKS}

As we have said, wood products were not included for the first commitment period of the Kyoto Protocol, although the UNFCCC (2003) already assumed different options for the inclusion of wood products in future commitment periods. The three main options were to consider the products as a separate activity, as a separate, nonsite specific pool, and as a separate pool attached to eligible activities and land areas.

The estimation of carbon stocks in products requires a two-step process, including both the quantifying and the accounting of the carbon. 
The quantifying step is based on the estimation of the quantity of carbon fixed in the products and the time that carbon keeps fixed, while accounting refers to the estimation of product and carbon fluxes between and within countries. Quantifying, as it is focused in this chapter, has a merely technical component, taking into account both the forest and the products. On the other hand, accounting has both technical and political components, due to relationships between countries, were the relationships between $\mathrm{CO}_{2}$-emitting and $\mathrm{CO}_{2}$-fixing countries stand out. These trends were:

\section{IPCC default approach}

This approach basically assumes there is no change in the size of the wood products pool. Emissions from harvested wood are attributed to the year of production and to the country of harvest. This method overestimates the emissions because it supposes that all the harvested wood is burned o disposed of in solid waste disposal sites, when, depending on the country, a large portion is usually converted into wood products.

Stock-change approach:

This method estimates the net changes in carbon stocks in the forest and woodproducts pool. Furthermore, it offers incentives to Sustainable Forest Management policies and to the use of bioenergy and long-lived products. Changes in carbon stocks in forests are accounted for in the country where the wood is grown (the producer country) and changes in the products pool are accounted for in the country where the products are used (the consuming country). In this way, the stock-change approach benefits the consuming countries and was the method preferred by a majority of the countries in the European Union.

\section{Production approach:}

With the production method, net changes in carbon stocks in the forests and in the wood-products pool are estimated, but all the changes are taken into account for the producing country: that is to say, only domestically produced wood is taken into account. All the changes are computed when, but not where, they occur. This method was rejected by the majority of UE countries.

\section{Atmospheric flow approach:}

The idea of the atmospheric-flow approach is to account for net emissions or removals of carbon to or from the atmosphere within the national boundaries, including when and where they occur. It focuses on consumption, and so both imports and exports are taken into account. This method clearly benefits producer countries with low consumption, because the producing country only reports emissions form harvesting while the consuming country does not increase its carbon pool with the imported wood products but must report the emissions when those products decay. 
Decay approach:

In a very similar way as it was described by Lizarralde et al., 2008, a new mixed approach based on the decay of carbon in products through the useful life has been added to the methodologies of accounting for harvested wood products.

In order to use this useful life, two options were described (Lizarralde et al., 2008): On the one hand, "half-life" refers to the time after which half the carbon placed in use is no longer in use, assuming a destruction function for the product unit (Skog \& Nicholson, 2000). On the other hand, "average lifetime” is the average time a product is in use, using a linear function of product decaying.

Nowadays, the first option seems likely to be the one used by several countries, assuming a decay equation guided by half-life.

All the methodologies can be used and depending of the consumption, production and import/export balance of each country, one method could work better than others. Nevertheless, the most important issue should be to have good available data (Tier 3). Unfortunately, in Spain, only data for some wood boards are available (Canals et al, 2014). Thus, the life cycle of the products can be defined as the group of transformations of a product from the harvesting until its final disposal in landfills or burning, including recycling and reusing.

When assuming the carbon sequestration by products, it is not only the storage of carbon which has to be accounted. The recycling fluxes and the substitution of other products appear as a key factor for the use of products in accounting methods.

In general, substitution is defined as any use of biomass that reduces the use of the non-biomass materials. According to data from the European Union, for the case of wood products, the impact of the substitution of materials on the mitigation of climate change can be even greater than the impact of the sequestration (UE, 2004). This impact on climate change derives from the fact that producing wood products consumes much less electric or fossil energy than producing other materials such as steel or concrete. It is demonstrated (UE, 2004) that producing a fixed quantity of concrete needs about the double of the energy needed to produce the same quantity of wood. In the case of steel and aluminium, this rate reaches tens of times the energy needed for producing wood. In order to calculate the effects of substitution, a simple index is used called the "substitution factor", and calculates the reduction of $\mathrm{CO}_{2}$ emissions due to the use of wood rather than other materials. The equation of this substitution factor is:

$$
S=\Delta C / \Delta P=\text { Increment of emissions / Increment of wood use }
$$




\subsection{Data}

The data used for this work came from the third National Forest Inventory and from inventory data measured for the last revision of the management plan of "Pinar Grande” forest, which was carried out in 1995. In the typical inventory, a summary of the number of trees and volume per diametric class is obtained. Furthermore, a cutting plan for the next ten years is proposed. This cutting plan is usually divided into: (i) regeneration cutting (in order to obtain optimal conditions for the regeneration of the stand by cutting down old trees) and (ii) thinning (for the better development of the stand). In a sub-sampling of the inventory, some trees were felled and the total height was measured. These measures are used to develop volume equations which provide information for the actual volume of the forest and for the cutting plan. In order to maintain the same example from the previous version of this chapter, no changes were made in data acquisition. Nevertheless, as it will be shown, new inventory technologies could have been used, where accuracy and spatial resolution are the main improvement factors.

\subsection{Methods}

The development of the process has been designed as follows: The availability of an inside-bark taper equation developed for the species in the study location (Lizarralde \& Bravo, 2005) made it possible to introduce data of the felled trees (Diameter at Breast Height and Total Height) in the cited equation. At the same time, this equation is part of Cubica (Rodriguez \& Broto, 2003) and CubiFor (Cesefor, 2007), a software and excel complement that resolves the equation and gives volume and product classification as outputs. In this way, assuming a mean tree for each diametric class, the product classification by diametric class is obtained. The global methodology flowchart is shown in Fig. 1.

The taper equation used for this purpose was developed for Scots pine, natural forests in Castile and León (Lizarralde \& Bravo, 2005) using for its development some plots included in "Pinar Grande", so that its adaptability to the present data set is supposed to be good. The equation is the following:

$$
d=\left(1+0.4159 \cdot e^{-16.733 \cdot h}\right) \cdot\left(0.7365 \cdot D B H \cdot(1-h)^{0.5869-0.8945(1-h)}\right)
$$

where: $\mathrm{d}$ = relative diameter

$\mathrm{h}=$ relative height

DBH $=$ Diameter at Breast Height

Although this equation is proved to accurately assess diameter change along the stem and, subsequently, the volume of trees, other equations, such as segmented ones, seem to work as precisely as the one used in the study (Rodríguez et al., 2015) 
A way to avoid some assumptions and lead with extensive inventory data is airborne LiDAR technology. LiDAR is a remote sensing active system that allows capturing a bog amount of data of a forest through an inertial system, a LiDAR sensor and gps positioning. This way, a point cloud of laser return of vegetation is created and using forest modelling techniques, it is possible to obtain certain forest variables in a spatially continuous way, For instance, for the purposes of this chapter, the whole area of Pinar Grande has available data and equations to relate the point cloud and volume can be developed. Thus, accurate and economically affordable volume estimation is obtained for the whole area, with data for 625 square meter cells. This technology, that it has been widely used for forest inventories during the last years, is going to play an important role as an accurate estimation of present forest situation and, subsequently, will help proposing new management and cutting plans.

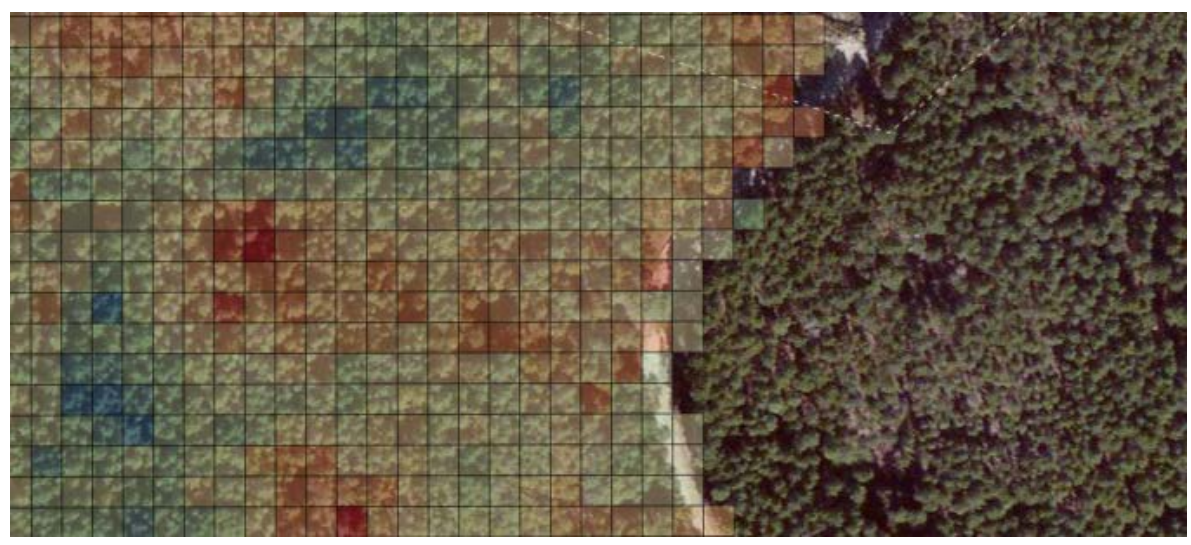

Figure 1. Example of LiDAR inventory cells with volume data and classification 


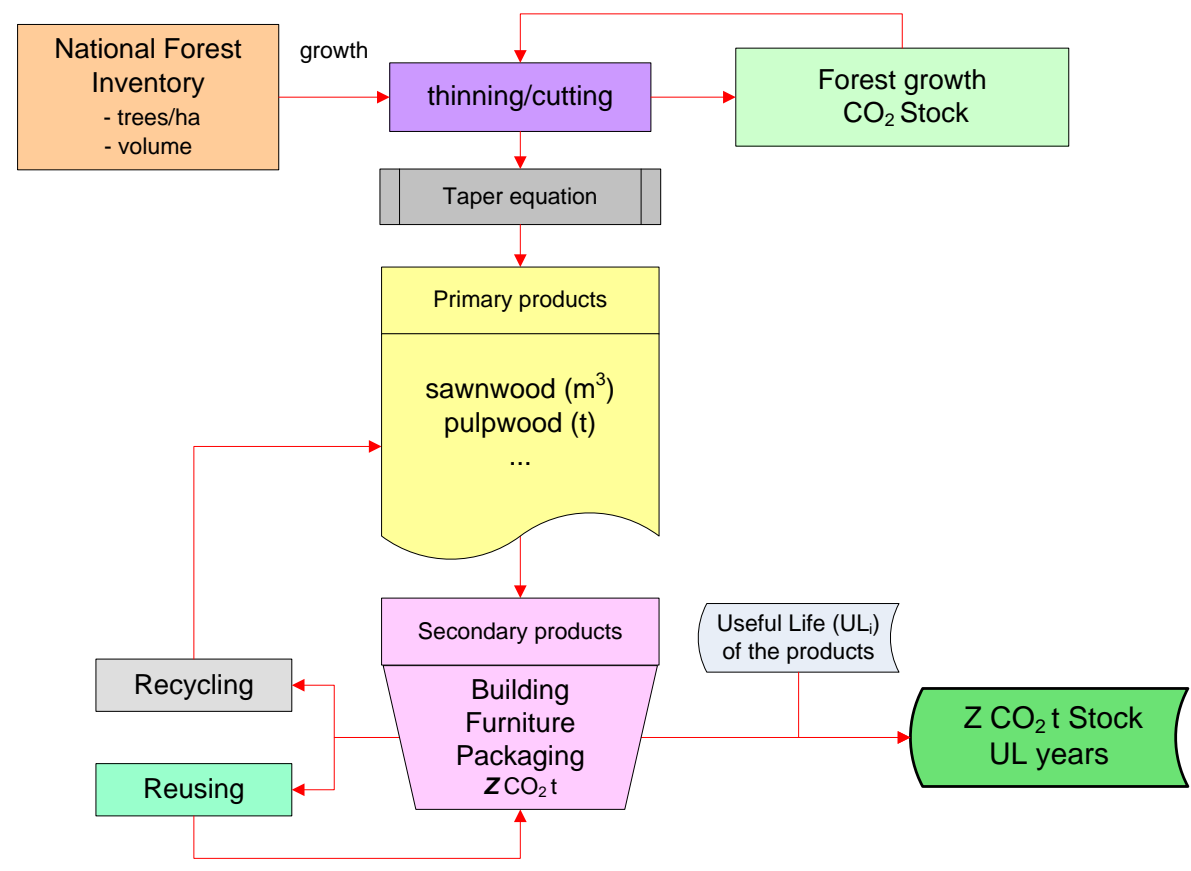

Fig. 2. Methodology for the calculation of the $\mathrm{CO}_{2}$ stored in wood products

The cutting plan proposes a certain number of trees from each diametric class to be felled. Thus, the volume of all the trees supposed to be felled in the next ten-year period can be calculated with a simple product classification (pulpwood and sawn wood). Thus, based on knowledge of the sector in the region, a more realistic classification was made, obtaining commercial products through manufacturing yields of each product. Figure 3 shows the flowchart of the production of those products with the recycling fluxes.

With the addition of recycling yields and useful life data, all the wood volume per product is calculated for a ten-year period and with continuing cycles of ten years, a simulation of carbon sequestrated is made for 50 years. Useful life calculation is based on experience of the sector, species and location from a conservative point of view, and may not agree with other assumptions (Row \& Phelps, 1996; Dias et al., 2005). In Fig. 4, the useful life periods for each product are shown: 


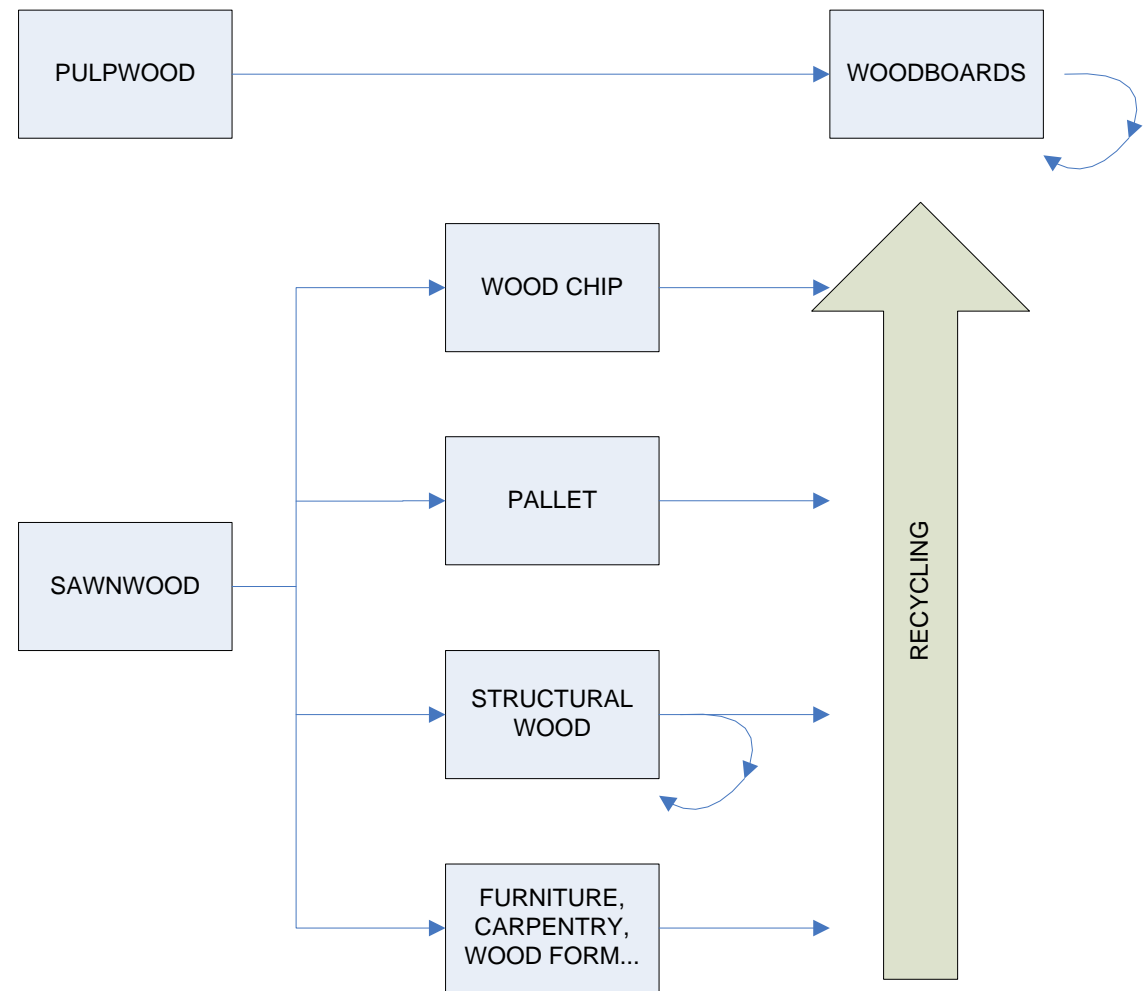

Figure 3. Flowchart of Scots pine wood production in Castilla y León with recycling fluxes 


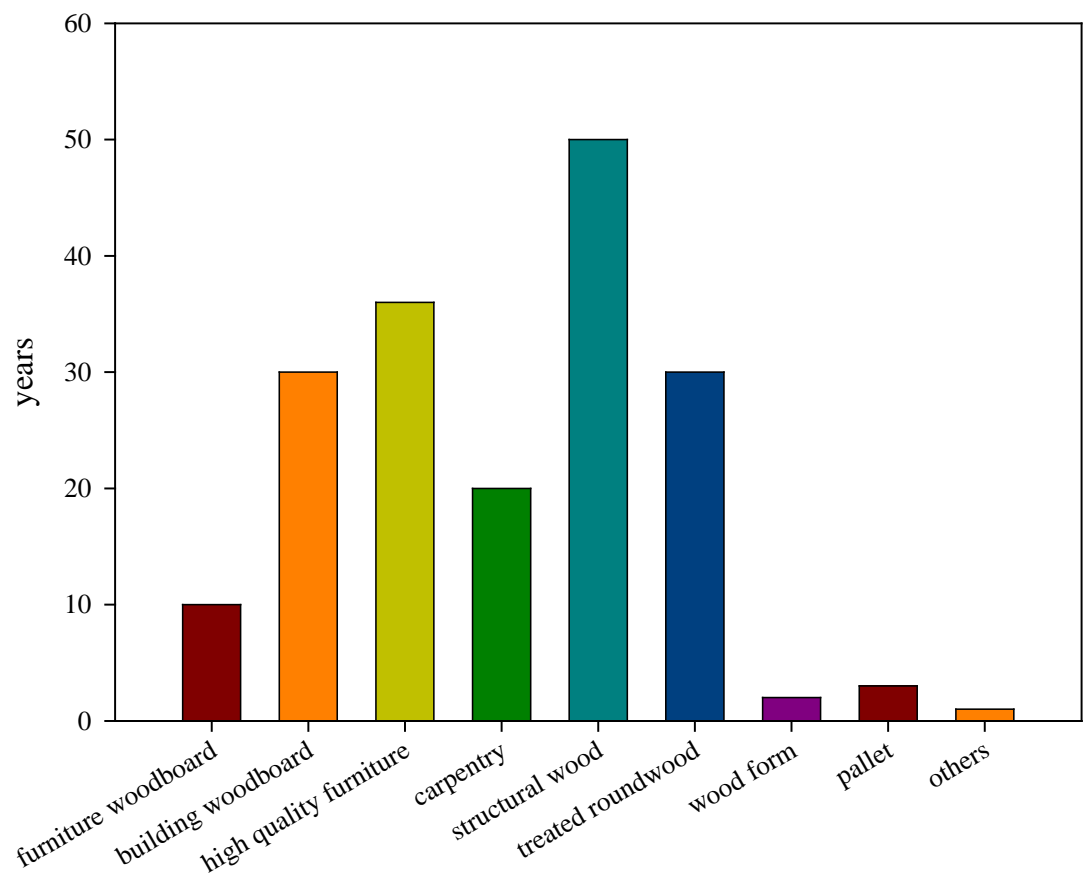

Figure 4. Useful life of the obtained wood products in the process

The calculation of useful lives was made via the basic useful life of each product, weighted with their importance and taking into account residues, sub-products and recycling. Thus, in order to know the time the carbon remains out of the atmosphere it is necessary to know the secondary products which are going to be produced. Useful life (ULi), reusing (using again the same product) and recycling (using the product to make new products, basically boards and paper) rates are assigned for each product. The final carbon storage is obtained by calculating a weighted useful life with the percentage of the primary product that goes to every secondary product. Equation 3 shows an example of this methodology:

$$
U L i=\% j \cdot U L j+\% k \cdot U L k+\ldots+\% n \cdot U L n
$$

Where ULi is the useful life of the primary product $i$

ULn is the useful life of the different secondary products

$\% \mathrm{n}$ is the percentage of primary product $\mathrm{i}$ that goes to secondary product $\mathrm{n}$

When a product is reused or recycled, a new useful life is assigned and added to the original useful life in order to obtain the total life of the product. 


\section{RESULTS AND DISCUSSION}

In order to see the importance of products on the global accounting of $\mathrm{CO}_{2}$, some examples are presented. Castile and Leon is the most important region in Spain from a forest point of view. It is estimated that the forests of the region accumulate every year about 12 million $\mathrm{CO}_{2}$ tons. If the sequestration by the products is added to this number, the global sequestration may reach up to 15 million tons. The 3 million tons are obtained from a strong thinning simulation for a 50-year time span, where the objective is to maximize the sequestration of $\mathrm{CO}_{2}$ based on the elaboration of products with a long, useful life.

In order to obtain a management plan which optimizes the carbon sequestration, three different management paths were simulated and a "nonmanagement" path was included in the comparative analysis (table1). The fixed management plans were taken from two yield tables for Scots pine in Spain. One of them is a strong thinning proposal from a yield table for the Iberian range, Path2 (García-Abejon, 1981) and the other is a moderate proposal from the yield table for the species in the Guadarrama range, Path3 (Rojo \& Montero, 1996). The path named "Path1" is the one proposed in this chapter and its objective is to maximize carbon pools based on strong cutting paths.. With these different silvicultural options, a simulation of the evolution of carbon stock (in forest and products) was done for the next 50 years. Table 2 shows the evolution of $\mathrm{CO}_{2}$ with the different silvicultural paths.

Table 1. Thinning percentage by diametric class for Scots pine with different management paths.

\begin{tabular}{|c|c|c|c|c|}
\hline DC & No cutting & Path1 & Path2 & Path3 \\
\hline 10 & $0,0 \%$ & $20,0 \%$ & $50,3 \%$ & $44,2 \%$ \\
\hline 15 & $0,0 \%$ & $20,0 \%$ & $38,6 \%$ & $39,6 \%$ \\
\hline 20 & $0,0 \%$ & $20,0 \%$ & $29,7 \%$ & $35,0 \%$ \\
\hline 25 & $0,0 \%$ & $30,0 \%$ & $22,8 \%$ & $30,4 \%$ \\
\hline 30 & $0,0 \%$ & $20,0 \%$ & $17,5 \%$ & $25,8 \%$ \\
\hline 35 & $0,0 \%$ & $37,0 \%$ & $13,4 \%$ & $21,2 \%$ \\
\hline 40 & $0,0 \%$ & $45,0 \%$ & $10,3 \%$ & $16,6 \%$ \\
\hline 45 & $0,0 \%$ & $45,0 \%$ & $7,9 \%$ & $12,0 \%$ \\
\hline 50 & $0,0 \%$ & $40,0 \%$ & $6,1 \%$ & $7,4 \%$ \\
\hline 55 & $0,0 \%$ & $40,0 \%$ & $4,7 \%$ & $2,8 \%$ \\
\hline 60 & $0,0 \%$ & $40,0 \%$ & $3,6 \%$ & $2,8 \%$ \\
\hline 65 & $0,0 \%$ & $45,0 \%$ & $3,6 \%$ & $2,8 \%$ \\
\hline 70 & $0,0 \%$ & $45,0 \%$ & $3,6 \%$ & $2,8 \%$ \\
\hline
\end{tabular}

Where Path1 is the silvicultural option proposed in this chapter, Path2 is the yield table of García-Abejón (1981) and Path3 is the yield table of Rojo \& Montero (1996) 
Table 2. $\mathrm{CO}_{2}$ evolution on growth, products and globally for different silvicultural paths. The "Authors" path is the proposed in this chapter

\begin{tabular}{|c|c|c|c|c|c|}
\hline \multirow{2}{*}{ Paths } & \multicolumn{5}{|c|}{ years } \\
\cline { 2 - 6 } & 10 & 20 & 30 & 40 & 50 \\
\hline \multicolumn{7}{|c|}{ Growth $\left(\mathrm{CO}_{2}\right.$ tones $)$} \\
\hline No cutting & 15.977 .417 & 16.170 .680 & 11.192 .515 & 5.281 .162 & 2.161 .514 \\
\hline Path1 & 1.110 .201 & 762.636 & 54.506 & -874.599 & -1.275 .781 \\
\hline Path2 & 7.170 .277 & 7.697 .776 & 8.145 .751 & 8.557 .277 & 8.974 .851 \\
\hline Path3 & 4.643 .226 & 1.259 .296 & -722.365 & -1.596 .384 & -1.938 .542 \\
\hline \multicolumn{7}{|c|}{ Products (CO $\mathrm{CO}_{2}$ tones) } \\
\hline No cutting & 0 & 0 & 0 & 0 & 0 \\
\hline Path1 & 14.867 .216 & 29.801 .101 & 41.846 .954 & 53.616 .554 & 59.333 .896 \\
\hline Path2 & 8.807 .140 & 17.034 .699 & 21.206 .620 & 25.274 .917 & 27.849 .496 \\
\hline Path3 & 11.334 .191 & 24.977 .231 & 32.165 .208 & 37.741 .974 & 39.884 .001 \\
\hline \multicolumn{7}{|c|}{ Total $\left(\mathrm{CO}_{2}\right.$ tones $)$} \\
\hline No cutting & 15.977 .417 & 16.170 .680 & 11.192 .515 & 5.281 .162 & 2.161 .514 \\
\hline Path1 & 15.977 .417 & 30.563 .737 & 41.901 .461 & 52.741 .954 & 58.058 .115 \\
\hline Path2 & 15.977 .417 & 24.732 .476 & 29.352 .370 & 33.832 .193 & 36.824 .347 \\
\hline Path3 & 15.977 .417 & 26.236 .527 & 31.442 .843 & 36.145 .590 & 37.945 .459 \\
\hline
\end{tabular}

Where Path1 is the silvicultural option proposed in this chapter, Path2 is the yield table of García-Abejón (1981) and Path3 is the yield table of Rojo \& Montero (1996)

This data produce the following figure (Fig. 5), where it can be clearly seen how forest management leads to greater sequestration, taking into account both the forest growth and the products obtained from the harvesting. The differences between the used yield tables (García-Abejón, 1981; Rojo \& Montero, 1996) are not significant but the other two options are clearly different. The total balance during the first ten years is the same for all the paths because all the products are in their useful life. With the option of no cutting, growth rapidly starts to fall, and so the total balance is very low. On the other hand, the option proposed by the authors focuses on harvesting more large trees in order to obtain products with long useful lives which consequently leads to the greatest $\mathrm{CO}_{2}$ accumulation while it avoids carbon emissions from big, old trees if not harvested. 


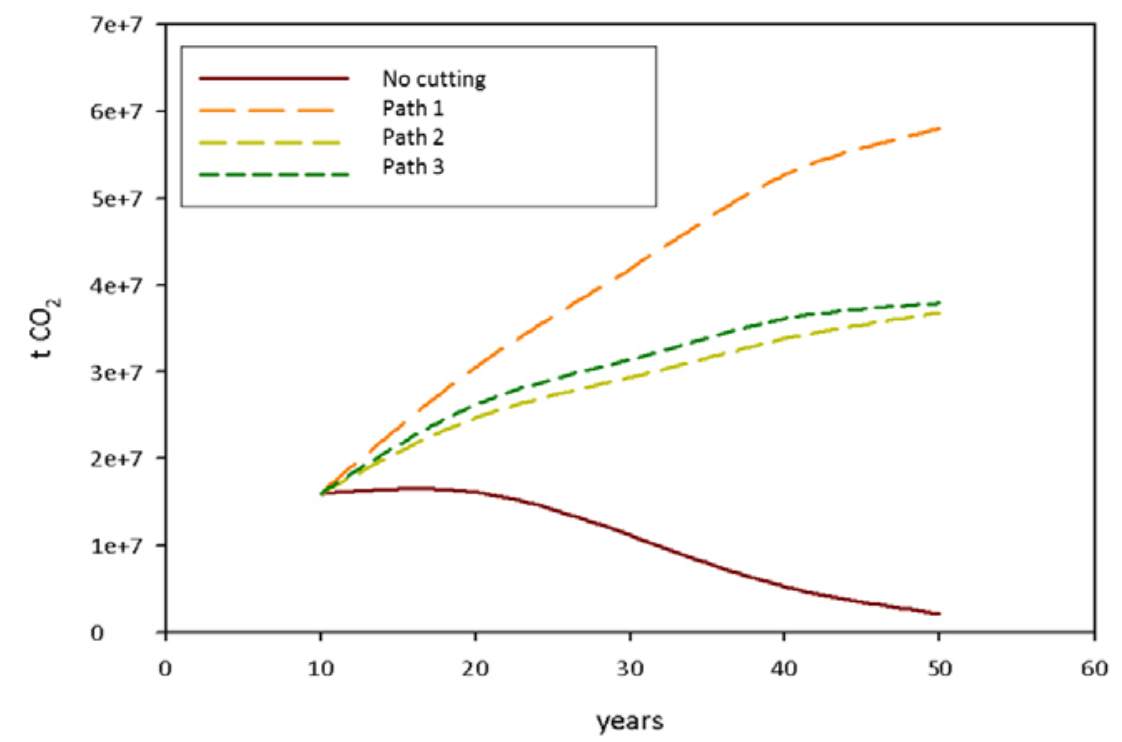

Figure 5. Comparative analysis of $\mathrm{CO}_{2}$ sequestration from different management paths for Scots pine in Castilla y León

Reducing the scope of the analysis (and in order to clearly show the importance of the management plans and the need of quantifying carbon pools on wood products), a case study from the even-aged Scots pine "Pinar Grande" based on the next ten years harvesting plan is shown.

The transformation of these volumes in products follows the usual rate of the industry for the species in this location, using most of the small-diameter wood for pulpwood which is transformed into boards and pallets, with a small part going to other products such as treated round wood. As the diameter gets larger, the assignment to sawn wood becomes bigger, although there is always a part devoted to board production. In Figure 6, the proportion of wood assigned to each product by diametric class is shown.

Once we have simulated the cutting plan with the distribution of products, the sequestration of carbon by the products can be obtained. The first step in the simulation is to calculate the sequestration in the first ten-year period. Introducing the different useful lives and the recycling fluxes, a longer simulation can be done. In this case, due to the maximum useful life assumed for the obtained products, a 50-year simulation was performed.

The final result of fixation in the 8750 ha of Scots pine in "Pinar Grande" is almost 600,000 tons of $\mathrm{CO}_{2}$ which will not be emitted to the atmosphere due to the 
manufacturing of wood products, as shown in Fig. 7. This value does not take into account externalities such as the fixation of workers in the area or more $\mathrm{CO}_{2}$ indirectly sequestrated by the substitution of other materials for wood. Moreover, in the period simulated only three recycling cycles are taken into account and the possible burning of the products is not observed, so that the final sequestration rate should be even bigger than what is shown.

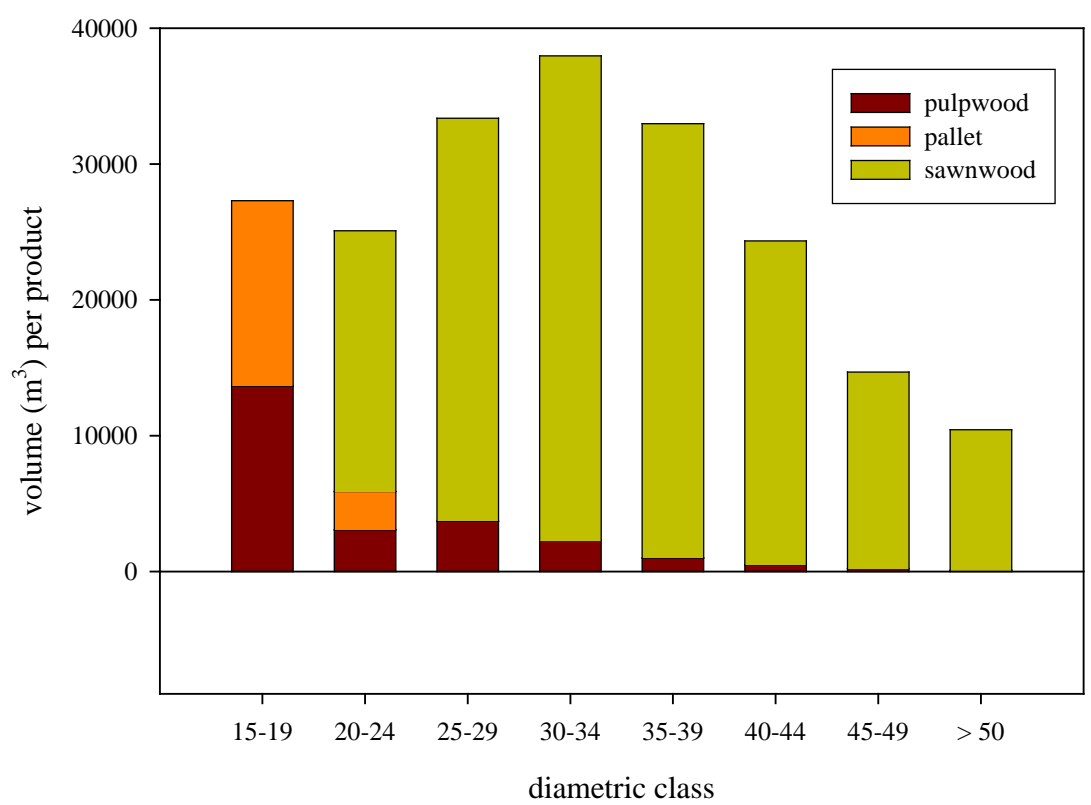

Figure 6. Distribution of volume per product for each diametric class 


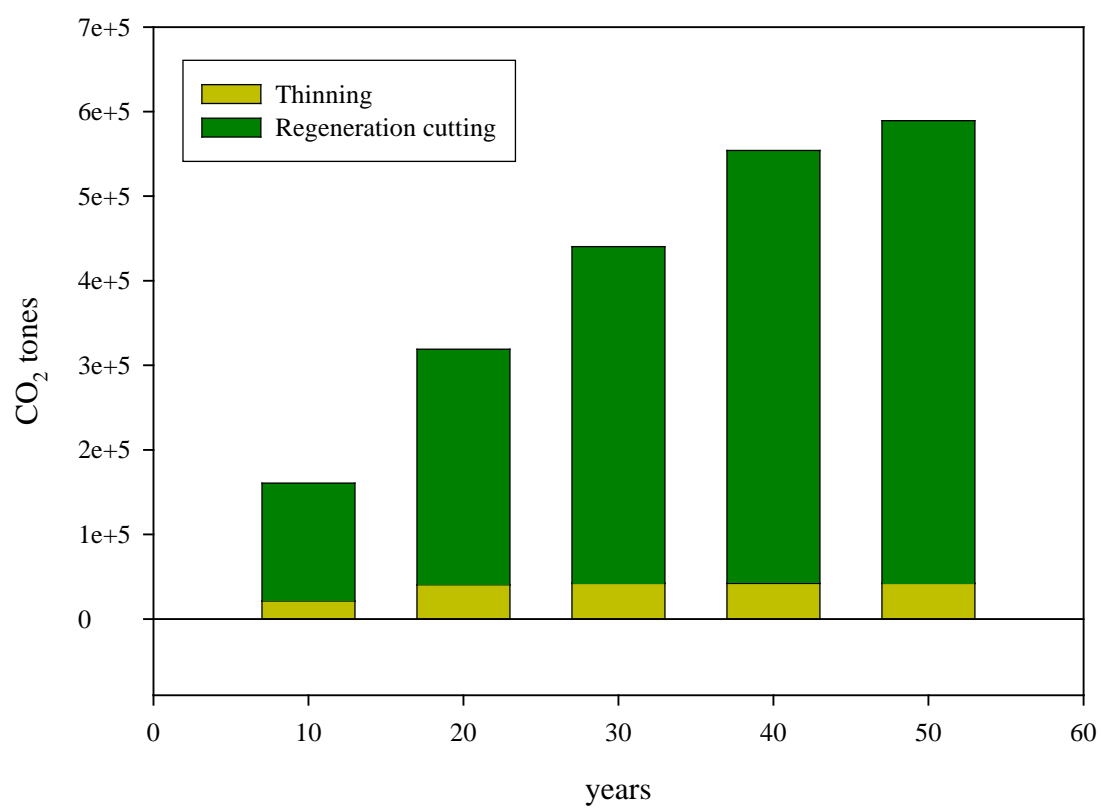

Figure 7.CO $\mathrm{CO}_{2}$ sequestration by Scots pine wood products for the next 50 years in "Pinar Grande”

The sequestration of the forest itself (taking into account only the stem of the trees) reaches some 750,000 tons of $\mathrm{CO}_{2}$. This means that the proposed harvesting level in the next 50 years will increase a \%78.8 the sequestration capacity of the forest and around $81.6 \%$ if the harvesting is concentrated in trees with diameter bigger than 35 $\mathrm{cm}$.

Thinning strategies have not a big influence in the carbon sequestration in themselves, but the products that those strategies can create in the future forest will increase the sequestration rates, in a $7.12 \%$ if the diameters reached are around 25 $\mathrm{cm}$ and even at $11.5 \%$ if the diameters are bigger than $35 \mathrm{~cm}$.

Table 3. Proposed volume to cut in "Pinar Grande" in a ten-year period

\begin{tabular}{|c|c|c|}
\hline Objective of cutting & Diametric class $(\mathrm{cm})$ & Volume $\left(\mathrm{m}^{3}\right)$ \\
\hline Thinning & $15-19$ & 27300 \\
\hline
\end{tabular}




\begin{tabular}{|c|c|c|}
\hline \multirow{4}{*}{ Regeneration } & $20-24$ & 25595 \\
\cline { 2 - 3 } & $25-29$ & 33711 \\
\cline { 2 - 3 } & $30-34$ & 38339 \\
\cline { 2 - 3 } & $35-39$ & 33300 \\
\cline { 2 - 3 } & $40-44$ & 24465 \\
\cline { 2 - 3 } & $45-49$ & 14754 \\
\cline { 2 - 3 } & $>50$ & 10442 \\
\hline
\end{tabular}

Recycling strategies do not have a very strong influence on the global sequestration rate. To give an example, for different products, a $20 \%$ variation in the recycling rate of a product only reflects a $2 \%$ variation in the total carbon sequestration in 50 years. It can be clearly seen that the important point is the decision as to what secondary product is better to produce for a certain forest, rather than the recycling rates this product will have in the future.

Another simple example to show the value of the forest products is to compare the carbon balance (emission-fixation) of products elaborated from different materials. The substitution of other materials for wood can be a very useful tool for decision makers to develop new strategies relating to the Kyoto Protocol. Some products have been chosen as examples of the importance of this issue. In this case, windows, building frames and utility and/or telephone poles are analyzed.

It is estimated that more than six million windows are produced every year in Spain. The balance of producing a window with wood is negative: that is to say, the carbon which the window absorbs is greater than the emissions due to the productive process of the window (about $0.32 \mathrm{CO}_{2}$ tons per house). Furthermore, producing a window with PVC or aluminium has a positive balance because there are only emissions and no fixation. In this way, and estimating 500.000 houses builded per year, the balance of substituting, for instance, aluminium for wood would represent more than 1.8 million $\mathrm{CO}_{2}$ tones (Lizarralde et al., 2007), enough to absorb the emissions of 750.000 cars. Although this data is no longer valid, as building capacity in Spain has been largely reduced due to the economic crisis (specially affecting building sectors), the fact of the carbon balance of substitution of aluminium by wood remains true.

In the case of building frames, Spain is a country with a very small tradition of building with wood compared with other countries in Europe, but substituting a concrete framework for wood in a single house means $20 \mathrm{t}$ of $\mathrm{CO}_{2}$.

Finally, producing all the utility and telephone poles in Spain with concrete may represent the emission of more than 3.6 million $\mathrm{CO}_{2}$ tones. Otherwise, if made with wood, 2.6 million $\mathrm{CO}_{2}$ tones could be absorbed, that is to say, the balance is of about 6.3 million tons or an energy saving of $18.000 \mathrm{GWh}$, around the $7 \%$ of the energy consumed in Spain. 


\section{CONCLUSIONS}

The use of taper equations and other forest modelling techniques, including product classification and the assessment of different management plans, as shown in this work, may lead to a better knowledge of carbon fluxes in forests and wood products. Thus, carbon-optimizing forest policies can be developed. The methodology developed allows not only carbon accounting but also an assessment of the "quality" of that carbon: that is to say, the time the carbon will remain in the wood product depending on its use.

The use of forest inventory technologies, such as LiDAR technology will help acquiring spatially continuous and precise data. In this way, more and better information will be available in order to develop broader studies of carbon budgets in forests and wood products.

The integration of the wood products in the global accounting of the carbon balances can represent a great advantage towards the accomplishment of the Kyoto Protocol, being as important as the forest growth. The first version of this chapter (Lizarralde et al., 2008) aimed to be a starting point to try to include them for the next commitment period (2013-2017). Nowadays, harvested wood products can be included in national carbon budgets. Nevertheless, few decisions and changes have been done in accounting methodologies. The use of wood products benefits us (i.e., society) from an environmental point of view. Hard work is needed to demonstrate these benefits to society and the policy makers but the final aim is worth while.

Forest management has to be the basis of the development of these kind of policies. The election of the management patterns and the products to be obtained is a key factor in assessing the real fixation of $\mathrm{CO}_{2}$. Forest management determines the products obtained from harvesting. In this way, silvicultural treatments and plans focused on sustainable management and obtaining long-lived products will optimize the global influence of our forests upon climate change, maintaining at the same time our natural resources.

\section{REFERENCES}

Canals, G.; Valero, E.; Picos, J.; Voces, R. (2014) Carbon storage in HWP. Accounting for Spanish particleboard and fiberboard. Forest Systems 2014 23(2): 225-235

Cesefor (2007). CubiFor, complemento de Excel para la clasificación de productos, cubicación y cálculo de biomasa y $\mathrm{CO}_{2}$. Departamento de $\mathrm{I}+\mathrm{D}+\mathrm{i}$. Cesefor. Internal document. Unedited. 
Dias, A.C.; Louro, M.; Arroja, L.; Capela, I. (2005). The contribution of wood products to carbon sequestration in Portugal. Annals of Forest Science, 62, 903909.

EU (2004). Comprenhensive report 2002-2003 regarding the role of Forest products for Climate change mitigation, from: http://ec.europa.eu/enterprise/forest_based/ccmreport.pdf

García-Abejón, J.L. (1981). Tablas de producción de densidad variable para Pinus sylvestris L. en el Sistema Ibérico. Comunicaciones INIA, Serie: Recursos Naturales, 29, 36 pp.

IPCC. (2000)a. Good practice guidance and uncertainty management in national gas inventories. IPCC Technical Report Unit, Hayama.

IPCC. (2000)b. Special report on Land Use, Land-Use change and Forestry. Cambridge University Press, Cambridge.

IPCC (2014) 2013 Revised Supplementary Methods and Good Practice Guidance Arising from the Kyoto Protocol. Hiraishi, T., Krug, T., Tanabe, K., Srivastava, N., Baasansuren, J., Fukuda, M. and Troxler, T.G. (Eds) Published: IPCC, Switzerland

Lizarralde, I.; Bravo, F. (2005). Análisis del espesor de corteza en ecuaciones de perfil para pino Silvestre (Pinus sylvestris L.) en Castilla y León. IV Congreso Forestal Nacional. Zaragoza.

Lizarralde, I.; Broto, M.; Rodríguez, F.; Bravo, F. (2008). Taper equations and wood products: assessing the carbon flow of the forest through its products. In Bravo, F. et al. (Eds.), Managing forest ecosystems: the challenge of climate change. Springer Science + Business Media B.V.

Rodríguez, F.; Broto, M. (2003). Cubica v1.2: Programa informático para cubicar y clasificar productos a partir de los datos procedentes de un inventario. Montes, 72, 21-29.

Rodríguez, F.; Lizarralde, I.; Bravo, F. (2015). Comparison of stem taper equations for eight major tree species in the Spanish Plateau. Forest Systems 24 (3) e034

Rojo, A.; Montero, G. (1996). El pino silvestre en la sierra de Guadarrama. Ministerio de Agricultura, Pesca y Alimentación. Madrid. 293 pp.

Skog, K.E.; Nicholson, G.A. (2000). Carbon sequestration in wood and paper products. In Joyce, L.S.; Birdsley, R. (Eds.), The impact of Climate Change on America's Forests: a Technical Document Supporting the 2000 USDA Forest Service RPA Assessment, Gen. Tech. Rep. RMRS-GTR-59. (pp 79-88) 
Department of Agriculture, Forest Service, Rocky Mountain Research Station, Fort Collins.

UNFCCC. (2003). Estimation, reporting and accounting of harvested wood products. Technical paper FCCC/TP/2003/7.

Werner, F.; Taverna, R.; Hofer, P.; Richter, K. (2005). Carbon pool and substitution effects of an increased use of wood in buildings in Switzerland: first estimates. Annals of Forest Science, 62. 889-902.

\section{AFFILATIONS}

I. Lizarralde, fora forest technologies, SLL

F. Rodríguez, fora forest technologies, SLL

F. Bravo, Sustainable Forest Management Research Institute University of Valladolid \& INIA, Dept. of Forest Resources, University of Valladolid, Palencia, Spain fbravo@pvs.uva.es 